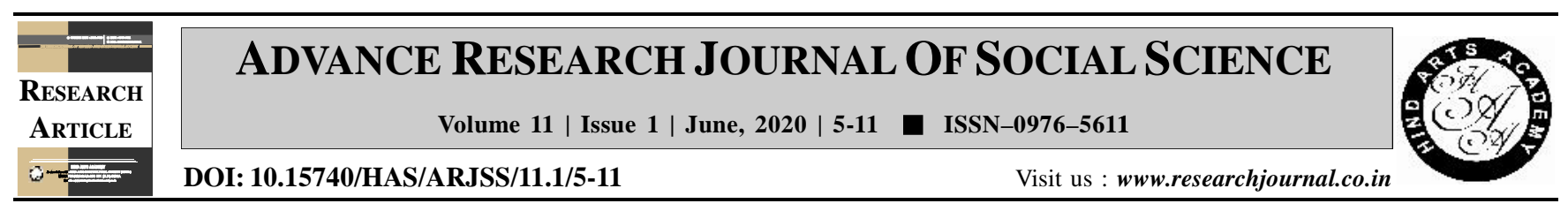

\title{
Socio-economic status of wheelchair users of Haryana
}

Anjali Gairola* and Kiran Singh

Department of FRM, IC College of Home Science (CCS HAU), Hisar (Haryana) India

(Email : anj.10.gairola@gmail.com; kiransingh.in@gmail.com)

\section{ARTICLE INFO :}

\section{Received}

Revised

Accepted

: 07.04 .2020

: 17.04 .2020

: 09.05 .2020

\section{KEY WORDS :}

Disability, Differently abled,

Socio-economic, Wheelchair user

HOW TO CITE THIS ARTICLE :

Gairola, Anjali and Singh, Kiran (2020).

Socio-economic status of wheelchair users

of Haryana. Adv. Res. J. Soc. Sci., 11 (1):

5-11, DOI: 10.15740/HAS/ARJSS/11.1/

5-11.Copyright@2020:Hind Agri-

Horticultural Society

*Author for correspondence

\begin{abstract}
Disability is something that limits a person's ability to engage in certain task or action which can be physical, mental or cognitive. In context of India 2.21 per cent population falls under disability criteria. Haryana also holding a large number of differently able persons who are looking forward for easily accessible environment and equitable opportunities. Socio-economic status of the locomotive disabled is significantly dependent on the educational level and occupation bread earner of the family and their family income. Head of the family of differently abled respondents of Haryana having education upto metric but still majority is involved in unskilled tasks. Socioeconomic status of the families with Disabled person has almost equal proportion in upper middle, lower middle and upper lower socio-economic class.
\end{abstract}

